\title{
Sex under pressure
}

\section{If sex is so important for evolution, why don't we have more of it?}

\author{
Why We Do It: Rethinking Sex and \\ the Selfish Gene \\ by Niles Eldredge \\ W. W. Norton: 2004. 224 pp. $\$ 24.95$
}

\section{Robert Foley}

I opened this book with considerable anxiety. The blurb and advance praise on the back make clear that Why We Do It (have sex, that is) aims to shatter myths, recast darwinism and fundamentally change the way we understand our own evolution. Niles Eldredge, an invertebrate palaeontologist and one of the major figures in the macroevolutionary debates of the 1970s and 1980 s, sets out to tear down the whole edifice of reproduction-driven neodarwinian behavioural and evolutionary ecology. If Eldredge's explicit idea is correct, then anyone reading this book should emerge completely purged of the orthodox model of evolution as a process of enhancing reproductive success. No wonder I was anxious.

Eldredge's argument is straightforward. Sex for most animals, including or even especially humans, does not happen very often. Most of life is filled with growing up, finding enough to eat and avoiding predators. Sex is only occasionally interspersed among these activities - I leave it to other readers to quantify this, as I suspect there must be considerable variation. Indeed, this is one of Eldredge's main points: there are some individuals - and we're talking about humans here - who never have sex. What follows from this, Eldredge argues, is that because sex is relatively rare, it must, in evolutionary terms, be relatively unimportant.

The next step in the argument is that sex is the source of the 'selfish gene' or 'genecentred' model of evolution, so this model clearly must be wrong. Selection is not for sexual and reproductive success alone, but affects all the other events between birth and death. As Eldredge says, life is for living, not for having sex and reproducing, so fitness for life - not for the ability to spread genes is what the game is all about.

Eldredge then sets out to establish that there are, within the arena of evolution, two separate spheres: reproduction and economics (drawing on some of Darwin's original formulations). Selection operates on both of these independently and, if anything, selection for economic factors is more important than selection for reproductive success, on the grounds that more effort goes into it. From this point comes a battery of assaults on the role of evolution in human behaviour: the dismissal of evolutionary psychology, the dominance of culture over biology,

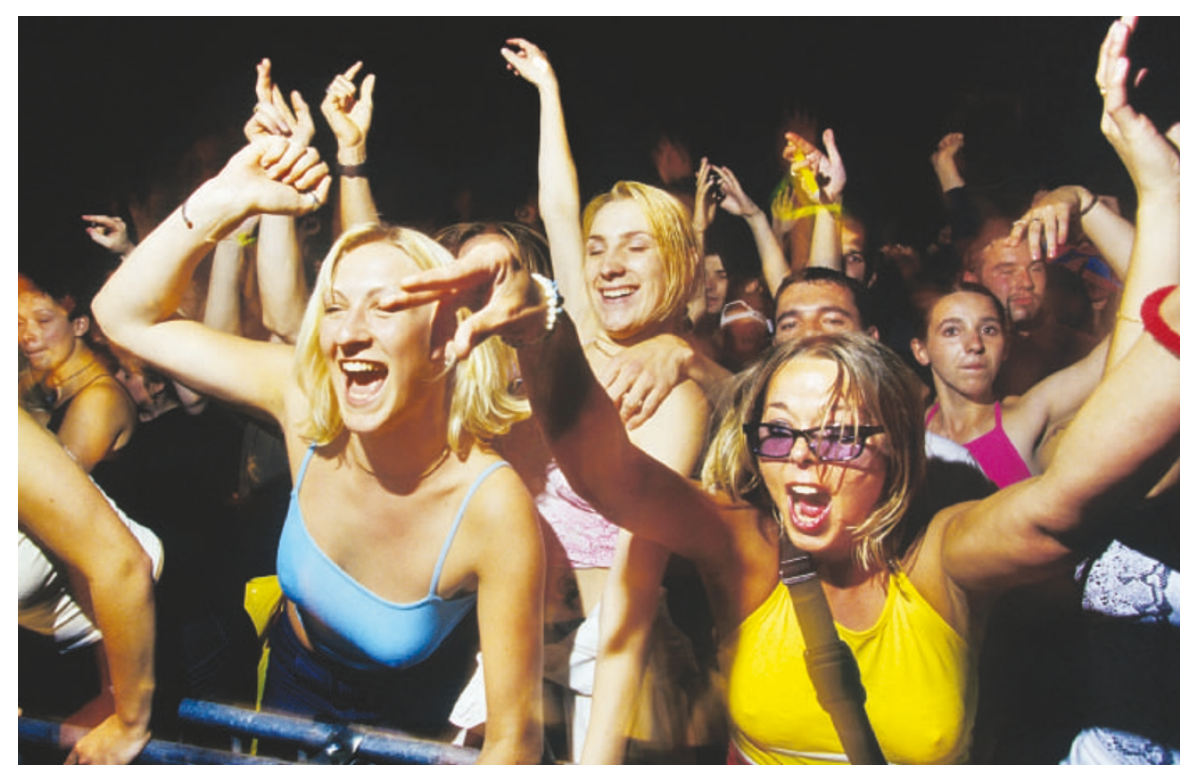

Life is for living: selection affects every aspect of our lives, so does it all come down to sex?

the separation of sex from reproduction in humans (reducing even more the significance of reproductive success), and an attack on biological determinism in human affairs.

At heart, the book is deeply anti-gene. It argues that genes are wrongly placed at the centre of evolutionary theory, that genes do not play an active role in the evolutionary process, that genes do not greatly influence human behaviour, and that the genetic heritage of human evolution is not significant.

Is this the end for those Eldredge portrays as the ultradarwinists - notably Richard Dawkins, E. O. Wilson, all evolutionary psychologists and probably most behavioural ecologists? Has Eldredge demolished genecentred evolutionary theory? Hardly. The logical error in Eldredge's argument is so breathtakingly obvious that one can only wonder how he has missed it. Reproductive success is not just about having sex. Take virtually any animal, and certainly it may spend relatively little time actually copulating, but what Eldredge isolates as the economic sphere is clearly not independent of sex and reproduction. How an organism grows - with males of many species being larger than females, for example - is not an isolated biological phenomenon, but represents an individual (through its genes) positioning itself to compete well in the reproductive arena. Its social behaviour, being competitive or cooperative, and its feeding ecology are all part of its reproductive strategy - and hence are selected not just for their own efficiency, but for the extent to which they contribute to reproductive success. Countless studies across vast numbers of species have shown how patterns of 'economic' behaviour are related to reproductive strategies and success.

Humans are the central concern for Eldredge. It is to his credit that his primary argument is not that selfish-gene models do not apply to humans because they are different, but that selfish-gene models do not work for any organisms, and therefore apply even less to humans. Ultimately, as the final chapters make clear, this book sees in classic neodarwinism the dangers of biological determinism, and views evolutionary psychology in particular as the modern version of the older threats of social darwinism and eugenics. There is plenty on humans here, but whether this has much to contribute to debates on the relative roles of genes and the environment in human behaviour, and on whether human behaviour is shaped by strategic concerns over reproductive fitness, is a matter of doubt. The evidence on human behaviour takes the form of anecdotes about how we do not have as much sex as we could, or how we sometimes behave in ways that do not obviously seem to enhance our fitness. Although such anecdotes are indeed abundant, they hardly constitute serious scientific study.

It may seem harsh to criticize so heavily a book written in such an extraordinarily popular and friendly manner - this is not a scientific monograph, after all. However, the claims made here are so strong, so polemical and so tilted towards making reproductive fitness seem like an irrelevance in the evolutionary process that it would be inappropriate not to point out the extent to which 
a naive reader might be misled. There are many oversimplifications and difficulties with the strongly adaptive models of human evolution constructed by evolutionary psychologists and behavioural ecologists, but Eldredge's approach is too extreme to bring these out in any way that might usefully influence future developments.

Should you read this book? It is written in a chatty and homely style, which will appeal to some and grate on others. Even the notes provide little bibliographic support for the points made in the body of the book, being rather an extension of the polemic by other means. If you are in the mood for some relentless Dawkins-bashing, or want a rush of arguments against biological determinism, then you might enjoy it. But if you are a neodarwinian in search of a road-toDamascus experience, this is not the place to find it. And if you are a neodarwinian not looking for such an experience, you had better avoid this book, as its superficiality, inconsistency and misleading logic will only irritate. On the other hand, you need not have any fear of having your evolutionary world turned upside-down. I closed the book with a sigh of relief.

Robert Foley is in the Leverhulme Centre for Human Evolutionary Studies, University of Cambridge, Downing Street, Cambridge CB2 3DZ, UK.

\section{$\cdots \cdots \cdots \cdots \cdots \cdots \cdots \cdots \cdots \cdots \cdots \cdots \cdots \cdots \cdots$}

\section{The birth of}

\section{modern science?}

\section{The Forgotten Revolution: How Science Was Born in 300 BC and Why It Had To Be Reborn}

by Lucio Russo (transl. Silvio Levy)

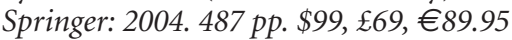

\section{Mott Greene}

The Forgotten Revolution is a work of passionate advocacy, defending the excellence of science in Greece in the 200 years after the beginning of the Hellenistic period in 320 BC. The author, Lucio Russo, a professor of mathematics at the University of Rome, has an appetite for classical works of science in their original Greek and Latin, and is on a spirited crusade against two groups. His first target are those "moderns" who (apparently) lump everyone from the Greek philosopher Thales in the sixth century BC to Ptolemy, an Egyptian astronomer of the second century $\mathrm{AD}$, into an undifferentiated mass called the Ancients, and then disparage their intellects and scientific achievements. The second group are the classicists, who are accused of treating everything that came after Athens in the fourth-century BC, and the Hellenistic world in particular, as a technically proficient but intellectually

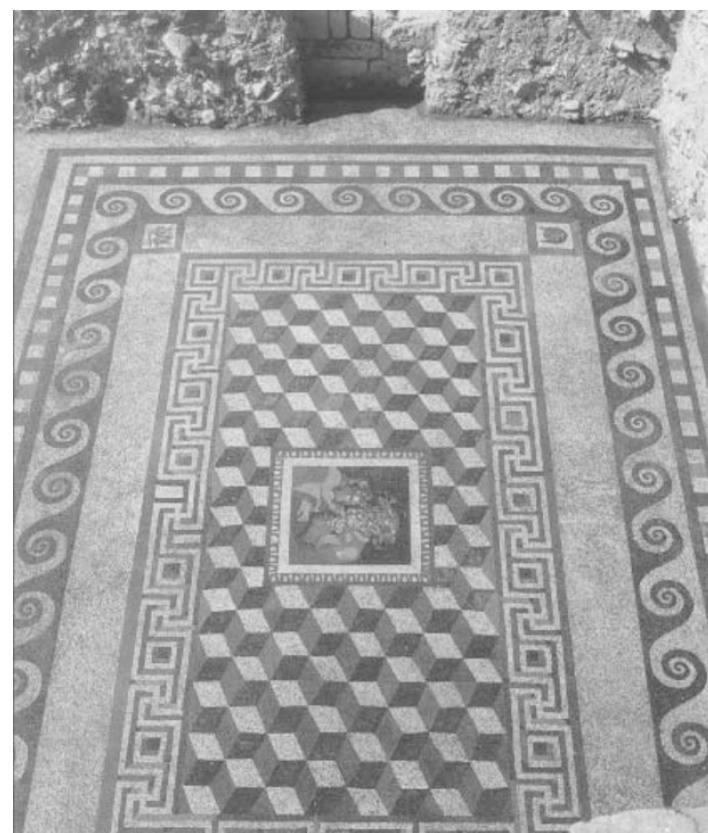

Just a regular floor? Hellenistic design often drew on geometry.

and to find much after the second century BC decadent. The argument is nonetheless stimulating.

Fortunately for the reader (although more or less in contravention of the book's central premise), Russo no sooner limits science to hypothetico-deductive reasoning than he drops that stricture. This lets in lots of wonderful science, technology and medicine, achieved in the Hellenistic period by observation, description, approximation and induction. If we were stuck with his stricter definition of science, then almost everything in the Hellenistic world, and certainly everything in this issue of Nature, would not count as real science.

Russo is entitled to his own opinions but not to his own facts. There are some errors and bold exaggerations: caveat lector. His attempt to suggest that Ptolemy's

uninteresting successor to the classical world.

If this is a fair portrayal of these groups then Russo is right to take up the cudgels, for the Hellenistic period is a brilliant episode in the history of science, and our own mathematical and physical sciences are built on its foundations. The connections between Russo's "forgotten revolution" and the scientific revolution of the seventeenth century are immediate and direct. The surviving treatises of Hellenistic mathematics, translated from Byzantine codices in the late sixteenth century, were essential to Descartes, Galileo, Kepler and Newton.

Russo presents an enticing vision of a Hellenistic world with a highly organized scientific effort that lasted for centuries. He sees government support for science, libraries and institutes. He sees science with technological applications, if not an industrial scale. He views the Hellenistic development of geometrical proof into a hypotheticodeductive method as the revolutionary birth of true science. If there is anything you like in modern science and mathematics (or art, linguistics, architecture, technology or medicine), he is glad to show you that the Hellenistic Greeks had already been there and done that. He is even pretty sure they had the inverse-square law of gravitation.

Is this vision true to the facts? A great deal of it is, yes, but not all, and certainly not the bit about the inverse-square law. Yet the effort to spin out the "what if...?" is well worth it. We have access to only $1-2 \%$ of these ancient texts for which we know the titles, the rest being lost, which leaves a good deal of room for Russo to imagine a Hellenistic science much more ample and more modern than previously thought. There is a corresponding tendency to downplay the quality and quantity of science before the fourth century $\mathrm{BC}$,
Almagest "presents a system for predicting the motions of the planets but no explanation of how the system was obtained" is both untrue and unfair, although Russo's thesis that Ptolemy belonged to a decadent age requires it. Ptolemy actually provided a beautiful, original, rationally organized description of all the key parameters, including how to derive them from observation, and how to obtain these observations under minutely specified conditions. The interested reader is referred to James Evans' The History and Practice of Ancient Astronomy (Oxford University Press, 1998).

Indeed, much of the history of science referred to by Russo resides in standard works published over the past 50 or so years. It seems he has not recently renewed his acquaintance with the subject through the technical literature, although he has read widely among the popular works. This does not undo the worth and verve of his presentation, but the sheer volume of recent work does undo his 'conspiracy of silence' thesis. Try using Google to track down a Greek name - Aristarchus of Samos, say - and you'll see what I mean.

Russo's book left me feeling that I would have loved to live (and might well have found a good job) in third-century Alexandria. The copious, informative and useful illustrations in this beautifully produced volume intensify the sense of what was lost when this great civilization went into decline and perished. They also inspire a sense of where we might be, had that "lost revolution" continued unchecked from 2,000 years ago to today. Would we be travelling to the stars? "One may imagine..."

Mott Greene is in the Department of History, University of Puget Sound, Tacoma,

Washington 98416, USA. 